(SIE); or as a further, poorly characterised form of $\mathrm{AD}$ skin peeling, termed epidermolysis bullosa simplex superficialis (EBSS), previously described in two families.

We report 6 affected individuals from 2 generations with generalised $\mathrm{AD}$ skin peeling. All presented neonatally with erosions at trauma-prone sites including the axillae, back and thighs, with ongoing skin fragility caused by friction. All 4 affected children reported slightly dry skin in the first decade of life with very mild hyperkeratosis of the axillae and neck. Some individuals had peeling of fingertips and soles, and one adult had mild diffuse plantar hyperkeratosis. There was no erythema, mucosal, nail or hair involvement. Initially, EBSS was considered based on $\mathrm{AD}$ inheritance, the generalised distribution, and lack of inflammation and ichthyosis at presentation.

A biopsy of rubbed, uninvolved skin from one affected individual showed a thickened stratum corneum but no signs of blistering or ultrastructural abnormalities at the dermal-epidermal junction or within the epidermis. Sequencing of KRT5 and KRT14 (keratins 5 and 14) showed no mutations, but whole exome sequencing demonstrated a heterozygous missense mutation in KRT1 encoding keratin 1, p.Ser338Pro, in the 4 probands tested. This amino acid substitution is located within the L12 linker region, close to where other pathogenic mutations in keratin 1 have been reported in unrelated individuals with EI. Therefore, the most likely diagnosis in this family is EI due to a novel mutation in KRT1

This clinically mild disorder and new KRT1 gene pathology extends genotype-phenotype correlation in EI and underscores the value of next generation sequencing in diagnosing clinically atypical genodermatoses.

\section{G29 A CASE OF PHYLLOID HYPOMELANOSIS - A RARE BUT SPECIFIC PRESENTATION OF CHROMOSOMAL MOSAICISM}

doi:10.1136/archdischild-2013-304107.042

'L Solman, 'M Glover, 1,2VA Kinsler. 'Paediatric Dermatology Department, Great Ormond Street Hospital, London, UK; ${ }^{2}$ Clinical and Molecular Genetics Unit, UCL Institute of Child Health, London, UK

This 18 month old boy presented with a history of hypopigmented macular lesions, mild neurodevelopmental delay and recurrent episodes of acrocyanosis with tachycardia and increased tone. The cutaneous lesions developed from the age of 3 months, affecting the right trunk and right upper and lower limbs. Examination revealed large well-defined hypopigmented macules in a classical phylloid pattern, with a midline cut-off anteriorly and posteriorly on the trunk, compatible with a diagnosis of phylloid hypomelanosis. Mild facial dysmorphism was noted. Neurodevelopmental assessment at the age of 12 months suggested mild global delay; EEG and MRI of the CNS are pending. Cardiovascular examination was normal, however 24 hour ECG revealed non-specific ST segment changes. Ophthalmologic assessment was normal. Array comparative genomic hybridisation on a peripheral blood sample was normal. Karyotyping of affected and unaffected skin fibroblasts is underway.

Phylloid hypomelanosis (Greek phyllon $=$ leaf, eidos $=$ form) is characterised by congenital hypopigmented macules resembling a floral ornament, with round, oval or oblong patches (1), distinct from the commoner Blashko-linear distribution. It is a rare but highly specific sign of chromosomal mosaicism, universally associated thus far in the literature with mosaicism for duplications of $13 q$ (1.2). Associated extracutaneous anomalies vary, and can include neurological, ocular, dental and skeletal defects (2). Cardiovascular abnormalities have not been reported thus far, and followup in our patient will clarify whether this is an associated or incidental feature. Affected individuals require multi-disciplinary assessment and long-term follow-up. As this is a somatic mosaic condition the possibility of fully affected offspring from the probands should be addressed at an appropriate age.

\section{REFERENCES}

1. Phylloid hypomelanosis is closely related to mosaic trisomy 13. Happle R. Eur J Dermatol. 2000 Oct-Nov; 10(7):511-2.

2. Phylloid hypomelanosis and mosaic partial trisomy 13: two cases that provide further evidence of a distinct clinicogenetic entity. González-Enseñat MA, Vicente A Poo P, Catalá V, Mar Pérez-Iribarne M, Fuster C, Geán E, Happle R. Arch Dermatol. 2009 May; 145(5):576-8.

\section{G30 DEVELOPING PAEDIATRICIANS AS FUTURE CLINICAL LEADERS: ENABLING DOCTORS IN OUALITY IMPROVEMENT AND PATIENT SAFETY (EQUIP) PROGRAMME DESIGN AND EVALUATION}

doi:10.1136/archdischild-2013-304107.043

1J Runnacles, ${ }^{2} \mathrm{~L}$ Linkson, ${ }^{2 P}$ Lachman. 'Paediatrics, Kingston Hospital NHS Trust, Kingston-upon-Thames, UK; ' ${ }^{2}$ Uuality, safety and transformation, Great Ormond Street Hospital for Children NHS Foundation Trust, London, UK

Aims Paediatric postgraduate training needs to prepare paediatricians for the future delivery of high quality care. Doctors in Postgraduate Training (DrPGT) are often best placed to identify safety/ quality concerns and can innovate across organisational boundaries. To address this, a programme was developed at a large tertiary centre providing a supportive educational environment. Its aims are to allow experiential learning on an improvement project alongside teaching of quality improvement (OI) and systems theory.

Methods EQuIP (Enabling Doctors in Quality Improvement and Patient Safety) supports DrPGTs through a OI project within their department, aligned to Trust's objectives. A three level approach to the programme ensures DrPGT engagement. All DrPGTs participate in a $1 \mathrm{hr}$ workshop to understand the importance of $\mathrm{OI}$ (level 1). Level 2 is a 6-month rotational programme with 2 full day workshops on improvement methodology, project surgeries facilitated by managers, and mentoring with senior clinicians. Level 3 is more intensive, over a 9 month period, to develop expertise and deliver level 1 workshops. The innovation involves a peer-designed programme while being work-based, delivering organisational strategies. Pre- and post- programme questionnaires allow Kirkpatrick 4-level evaluation.

Results All 40 participants agreed that the project was a valuable learning experience and that the programme met their expectations (level 1, reaction). Level 2, learning, was demonstrated by an improvement in QI definitions post programme, awareness of QI resources and confidence in using methodologies including PDSA and process mapping $(\mathrm{P}<0.001)$. Post programme, all but one participant said they are planning another OI project and that they are more aware of improvement work in their unit (behaviour change, level 3). Benefits to the organisation (level 4) are evident from successful projects presented to the executive team showing reduction in DNA rates, improved theatre efficiency, improved quality of medical notes etc.

Conclusion EQuIP changes the way DrPGTs view healthcare as they become quality champions for their department. The design and evaluation of EQuIP may inform similar educational programmes in other organisations. This capacity building is crucial to ensure future Paediatric leaders have the skills and motivation to improve the effectiveness of our healthcare system.

\section{G31 USE OF TRANSLATED VERSIONS OF ROYAL COLLEGE OF PAEDIATRICS AND CHILD HEALTH (RCPCH) APPROVED PREM TOOL FOR PATIENT FEEDBACK IN AN ACCIDENT AND EMERGENCY DEPARTMENT DEALING WITH A MULTIETHNIC POPULATION}

doi:10.1136/archdischild-2013-304107.044

C Singh, L Alsford. Department of Paediatrics, North Middlesex University Hospital NHS Trust, London, UK

Aims The aim of our study was to collect feedback by using the RCPCH PREM tool for paediatric urgent and emergency care (A\&E), 